\title{
CAPÍTULO 08: CERVEJA ARTESANAL: COMPONENTES E PROCESSOS PRODUTIVOS
}

\section{CAPÍTULO 08: CERVEZA ARTESANAL: COMPONENTS Y PROCESOS DE PRODUCCIÓN}

\section{CHAPTER 08: CRAFT BEER: COMPONENTS AND PRODUCTION PROCESSES}

\author{
Higo Moreira de Assis ${ }^{1}$; Mônica Tejo Cavalcanti²; Mônica Correia Gonçalves ${ }^{3}$; Thamirys Lorranne Santos \\ Lima $^{4}$; Inês Maria Barbosa Nunes Queiroga ${ }^{5}$
}

DOI: https://doi.org/10.31692/978-65-88970-19-5.113-132

\begin{abstract}
RESUMO
A cerveja está presente em diversas culturas de diferentes países movimentando milhões anualmente e é uma bebida obtida a partir da fermentação alcoólica do mosto cervejeiro oriundo do malte de cevada, água potável e adição de lúpulo, por ação de leveduras, adicionados ou não de adjuntos, podendo ser produzida em diversos sabores e de formas variadas. Portanto, objetivou-se com esta pesquisa, realizar um levantamento bibliográfico à cerca da cerveja artesanal, como forma de compreender o processo de elaboração e seus respectivos constituintes. Esta pesquisa é de caráter exploratório e bibliográfico, onde realizou-se uma busca relacionada ao tema nos buscadores de maior facilidade de acesso. Este estudo foi estruturado em tópicos específicos, onde foi abordado desde a origem da cerveja até os componentes necessários para elaboração. Ademais, constatou-se neste estudo que geralmente, as cervejas artesanais possuem uma qualidade sensorial diferenciada quando comparadas as cervejas tradicionais. As cervejas populares têm o intuito de agradar à grande maioria dos consumidores de maneira mais barata possível, e conseguir manter um nível e padrão de qualidade invejável por qualquer empresa, devido ao controle que têm dos processos de produção, distribuição, etc. Enquanto as artesanais, têm o intuito de agradar um público restrito, no qual estão à procura de cervejas com características sensoriais diferenciadas das demais. Por fim, torna-se viável o conhecimento das questões que envolvem as principais características da cerveja artesanal, bem como do processo produtivo, como forma de promover o amplo acesso ao público consumidor de informações desta natureza, já que as cervejas são produtos altamente consumidos pela população em geral.
\end{abstract}

Palavras-Chave: Bebidas, Fermentação, Lúpulo, Mosto.

\section{RESUMEN}

La cerveza está presente en varias culturas en diferentes países, moviendo millones anualmente y es una bebida que se obtiene de la fermentación alcohólica del mosto cervecero a partir de malta de cebada, agua de bebida y la adición de lúpulo, mediante la acción de levaduras, agregadas o no con adyuvantes se puede producir en diferentes sabores y de diferentes formas. Por tanto, el objetivo de esta investigación fue realizar un relevamiento bibliográfico sobre la cerveza artesanal, como una forma de entender el proceso de elaboración y sus respectivos constituyentes. Esta investigación es de carácter exploratorio y bibliográfico, donde se realizó una búsqueda relacionada con la temática en buscadores de más fácil acceso. Este estudio se estructuró en temas específicos, donde se abordó desde el origen de la cerveza hasta los componentes necesarios para su elaboración. Además, en este estudio se encontró que las cervezas artesanales generalmente tienen una calidad sensorial diferenciada en comparación con las cervezas tradicionales. Las cervezas populares están destinadas a complacer a la gran mayoría de los consumidores de la manera más barata posible, y mantener un nivel y estándar de calidad envidiable para cualquier empresa, debido al control que tienen de los procesos de producción, distribución, etc. Si bien son artesanales, están destinadas a complacer a un público restringido, en el que buscan cervezas

\footnotetext{
${ }^{1}$ Bacharel em Química Industrial, UEPB-Campina Grande, higomoreira.assis@ gmail.com

${ }^{2}$ Doutora em Engenharia de Processos, UFCG-Pombal, monicatejoc@yahoo.com.br

${ }^{3}$ Doutora em Ciência e Tecnologia dos Alimentos, UFCG-Pombal, mnygoncalvez@gmail.com

${ }^{4}$ Docente do Curso Técnico Integrado em Alimentos, IFRN-Pau dos Ferros, thamirys.lorranne@ifrn.edu.br

${ }^{5}$ Doutora em Ciência e Tecnologia dos Alimentos, UFCG-Pombal, inesmaria@leaosampaio.edu.br
} 
con características sensoriales diferenciadas de las demás. Finalmente, se vuelve viable conocer los temas que rodean las principales características de la cerveza artesanal, así como el proceso de producción, como una forma de promover un amplio acceso al público que consume información de esta naturaleza, ya que las cervezas son productos altamente consumidos por población general.

Palabras Clave: Bebidas, Fermentación, Lúpulo, Mosto.

\begin{abstract}
Beer is present in several cultures in different countries, moving millions annually and is a drink obtained from the alcoholic fermentation of the brewing must from barley malt, drinking water and the addition of hops, through the action of yeasts, whether or not added with adjuncts, It can be produced in different flavors and in different ways. Therefore, the objective of this research was to carry out a bibliographic survey about craft beer, as a way to understand the process of elaboration and its respective constituents. This research is exploratory and bibliographic in nature, where a search related to the theme was carried out in search engines that are easier to access. This study was structured in specific topics, where it was addressed from the origin of the beer to the components necessary for elaboration. Furthermore, it was found in this study that artisanal beers generally have a differentiated sensory quality when compared to traditional beers. Popular beers are intended to please the vast majority of consumers in the cheapest way possible, and to maintain an enviable level and standard of quality for any company, due to the control they have of the production, distribution, etc. processes. While handcrafted, they are intended to please a restricted audience, in which they are looking for beers with differentiated sensory characteristics from the others. Finally, it becomes viable to know the issues surrounding the main characteristics of craft beer, as well as the production process, as a way of promoting wide access to the public that consumes information of this nature, since beers are products that are highly consumed by general population.
\end{abstract}

Keywords: Drinks, Fermentation, Hops, Must.

\title{
INTRODUÇÃO
}

De acordo com Decreto $n^{0}$ 6.871, de 4 de Junho de 2009, o Art. 36 define cerveja como "a bebida obtida pela fermentação alcoólica do mosto cervejeiro oriundo do malte de cevada e água potável, por ação da levedura, com adição de lúpulo" (BRASIL, 2009). A cerveja é vista como sendo a bebida alcoólica mais antiga (ARNOLD, 2005) e mais consumida (PATTINSON, 2006) no mundo. A mesma é produzida em diversos sabores e de formas variadas, obtida a partir da fermentação alcoólica do mosto cervejeiro oriundo do malte de cevada, água potável e adição de lúpulo, por ação de leveduras, podendo ainda ser adicionada de adjuntos (DINSLAKEN, 2016).

Produzindo cerca de 138,6 Mi hl/ano, o Brasil é atualmente o $3^{\circ}$ maior produtor de cerveja no mundo. A produção de cervejas artesanais vem crescendo com o passar dos anos, em 2017 cerca de $20 \%$ da produção nacional foi oriunda de cervejarias artesanais, situando o Brasil como um dos maiores fabricantes do mundo (SEBRAE, 2017; ASSIS et al., 2020). O mercado consumidor tem-se manifestado cada vez mais exigente no que diz respeito a requalificação e a reorganização na produção de bens de consumo, esse comportamento reflete diretamente sobre a produção recursos na busca or atender a demanda elucidada (MELO; SILVA, 2020). Tais preocupações são enfrentadas pelo setor de produção de cerveja, visto que as oportunidades demandam a constante busca por aperfeiçoamento dos produtos ofertados. dos requisitos nos projetos de produto. 
Segundo Ferreira et al. (2018) a produção e o consumo de cervejas artesanais no Brasil são singularizados a consumidores mais exigentes em termos de qualidade sensorial, entretanto, o produto entregue é diferenciado e o investimento na otimização dos processos de obtenção tem-se demonstrado menos oneroso. O sucesso é garantido por fatores como inovação, criatividade, tipicidade e autenticidade que caracterizam a cerveja artesanal como uma experiência que oferece prazer, senso de identidade e pertencimento, e reconhecimento social, além de cores, aromas, sons e sabores diferenciados (FERREIRA et a., 2019; KOCK \& SAUERBRONN; 2018).

Para a obtenção da cerveja, a matéria-prima utilizada é processada através da malteação e submetida à ambientes artificiais de germinação, passando pelos estágios de limpeza, maceração, germinação e secagem. Com o malte seco e limpo está pronto para utilizar no processo de fabricação da cerveja (PORTO, 2011). O Humulus lupulus, conhecido vulgarmente como Lúpulo, planta trepadeira pertencente à família da morácea e originária de zonas temperadas é utilizado para atribuir o sabor amargo da produção de cerveja. Inserido pela primeira vez na idade média, o Lúpulo, atualmente é considerado em nível mundial, como matéria-prima primordial para a fabricação de cerveja. Segundo o mesmo autor, no Brasil, o mercado cervejeiro é basicamente dividido entre as microcervejarias e as cervejarias de produção em massa, apesar de se discutir a inclusão de novas divisões visando diferenciar as cervejarias de porte intermediário (MARCUSSO, 2015).

Em seu processo de produção são utilizados não apenas ingredientes básicos de fabricação (água, malte, lúpulo e levedura), como também iguarias como café, pimenta, banana, gengibre, entre outros condimentos, gerando um valor agregado à cerveja (ALMEIDA \& BELO, 2017). As cervejarias artesanais, além de terem sua importância econômica, social e cultural, têm se mostrado uma excelente opção de negócio no atual cenário econômico brasileiro e apesar de representarem uma fatia de mercado relativamente pequena quando comparado aos grandes líderes, esse setor de cervejas especiais artesanais, oriundas desse nicho de mercado vem crescendo mais do que o setor das cervejas voltadas para as grandes massas populacionais (ASSIS et al., 2020).

Diante deste contexto, objetivou-se com esta pesquisa, realizar um levantamento bibliográfico à cerca da cerveja artesanal, como forma de compreender o processo de elaboração e seus respectivos constituintes.

\section{METODOLOGIA}

O delineamento desta pesquisa caracterizou-se como uma revisão sistemática, baseando-se em pesquisas por artigos científicos atuais em periódicos científicos indexados ao Portal de Periódicos da Coordenação de Aperfeiçoamento de Pessoal de Nível Superior (CAPES), no Google Acadêmico, na Scientific Electronic Library Online (SciELO), e na Science Direct. Os critérios de inclusão foram trabalhos publicados em português ou inglês, 
artigos na íntegra indexados nos referidos bancos de dados entre 2010 e 2020, utilizando os descritores: “origem da cerveja artesanal”, "situação mercadológica da cerveja artesanal”, “produção de cerveja artesanal". Foi utilizado como critério de exclusão artigos que não contemplassem a temática.

\section{RESULTADOS E DISCUSSÃO}

\section{Origem da Cerveja e Cerveja Artesanal}

Cerevisia ou cervisia é a denominação mais próxima da atualmente conhecida cerveja.Éo nome latino dado pelos gauleses à bebida feita de cevada e de cereais, em homenagem à Ceres, deusa da colheita e da fertilidade (MORADO, 2009). A cerveja é uma das bebidas alcoólicas mais populares do mundo por causa da sua disponibilidade, capacidade nutricional, refrescância, baixa potência de embriaguez e baixo custo (MORADO, 2015).

O mais antigo código referente à produção de cerveja é a Lei da Pureza (Reinheitsgebot), onde relatava que a cerveja devesse ser produzida somente com água, malte, lúpulo e levedura, instituída por Guilherme IV, Duque da Baviera, no dia 23 de abril de 1516. Hoje, é empregado o uso de outros ingredientes e também alguns aditivos alimentares (KUCK, 2008).

Segundo Dragone, Almeida e Silva (2010), a técnica de fabricação de cerveja é tida como tradição milenar, ocupando espaço na história da humanidade e toda sua evolução. Não se sabe ao certo a origem das primeiras cervejas, porém segundo Kunze (1997) acredita que a prática da cervejaria seja oriunda da região da Mesopotâmia, em que a cevada cresce em estado selvagem. Há registros que evidenciam que a cerveja maltada já era produzida na Babilônia em6000 a.C, embora foram os sumérios considerados como a primeira civilização a fabricar a cerveja. E, após a queda do império sumério, os babilônios aprimoraram a tecnologia de fabricação da cerveja.

Dragone, Almeida e Silva (2010) ressaltam que a prática de tomar cerveja no Brasil foi trazida por D. João VI, no início do século XIX, durante a permanência da Família Real Portuguesa em território brasileiro, época em que a cerveja era importada da Europa. Foi fundada em 1888, na cidade do Rio de Janeiro, a "Manufatura de Cerveja Brahma Villigier e Cia" e, poucos anos depois, em 1891, na cidade de São Paulo, a "Companhia Antarctica Paulista".

No processo de fabricação da cerveja, são utilizados grãos de cevada que passam pelo processo de malteação com a finalidade de produzir as enzimas diastásicas responsável pela 


\section{So/NR' 5
CIAGRO 2021}

conversão do amido (não fermentável) em açúcar (fermentável), nessas circunstâncias o grão de cevada passa a ser chamado de malte (SANTOS; DINHAM, 2006; MATSUBARA et al., 2014).

O sabor da cerveja é determinado pela matéria-prima, pelo tipo de processo e pela levedura utilizada, além dos compostos produzidos durante a fermentação e maturação, que exercem maior impacto nas características sensoriais da bebida (CARVALHO et al., 2007).

A cerveja do tipo Ale é considerado o processo mais antigo de produção de cerveja e passa por alta fermentação. Entre os estilos do tipo Ale, se destacam a Porte, Stout, Brow, Mild e Bitter, em que, geralmente, as cervejas têm cores claras, apresentam sabor de lúpulo acentuado e teor alcoólico entre $4 \%$ e $8 \%$. O tipo Lager é caracterizado pelo sabor suave, coloração clara e teor alcoólico entre 3\% e 4\%, sendo mais comuns e mais consumidas no mundo, inclusive no Brasil, cujas características da bebida são mais adequadas ao nosso clima. As principais variedades do tipo Lager são a Pilsen e a Bock (SIQUEIRA, 2007).

Até o ano de 2015, o Brasil ocupava o terceiro lugar no ranking mundial de produção de cerveja. O Investimento do setor cervejeiro contribuiu fortemente para o desenvolvimento econômico do Brasil, sendo visto como um dos mais relevantes da economia com investimento próximo aos R $\$ 20$ bilhões entre 2010 e 2014. Como possui um importante efeito multiplicador na economia, pode ser visto uma movimentação extensa da cadeia produtiva que foi responsável por 1,6\% do PIB e 14\% da indústria de transformação nacional, além de, gerar mais de 2,2 milhões de pessoas empregadas ao longo da cadeia produtiva (CERVBRASIL, 2015).

O Decreto $\mathrm{n}^{\circ} 6.871$ de 4 de junho de 2009 , que regulamenta a Lei $\mathrm{n}^{\circ} 8.918$ de 14 de julho de 1994, dispõe sobre a padronização, a classificação, o registro, a inspeção e a fiscalização da produção e do comércio de bebidas (BRASIL, 2009).

Ainda em análise, há o Projeto de Lei ${ }^{\circ}$ 5.191/13 proposto pelo Deputado Rogério Peninha Mendonça de Santa Catarina, com o objetivo de regulamentar a produção de cerveja artesanal que objetiva segregar o conceito de cerveja artesanal e definir as instituições que produzem adaptando a legislação para permitir o avanço regulamentado deste setor.

A cervejaria artesanal permite a produção de cerveja em pequena escala para consumo no local ou envasamento do excedente para venda ou consumo em outros locais. O envasamento pode ser feito em barris de aço inoxidável, latas ou garrafas de vidro. As capacidades de produção variam geralmente entre 1000 a 2000 litros por cozimento e o número de cozimentos por semana oscila entre um e cinco (CARVALHO, 2007). 
Água

A água é vista como elemento essencial para a produção da cerveja, representa $90 \%$ da constituição do peso da cerveja, suas características físicas e químicas são de fundamental importância para se obtiver uma cerveja de boa qualidade (MADRID et al., 1996). No Art. 13 do Decreto 6.871 , determina no $\S 7^{\circ}$ que a água destinada à produção de bebida deverá atender ao padrão oficial de potabilidade.

Portanto, antes de sua utilização a mesma deve ser submetida a análises físico-química destacando os parâmetros: de $\mathrm{pH}$, dureza, turbidez, cor, temperatura dentre outras, não importando a fonte que se obteve esse recurso hídrico (BRIGIDO; NETTO, 2006).

Broderick et al. (1977) consideram que a água cervejeira não deve satisfazer somente os requisitos gerais de água potável, mas também os requisitos básicos para assegurar o $\mathrm{pH}$ da massa, a extração do lúpulo, uma boa coagulação na cocção e na fermentação e o devido desenvolvimento da cor, do aroma e do sabor.

Atualmente, a tecnologia permite "calibrar" as propriedades da água conforme as necessidades e a formulação, podendo acentuar sabores maltados e de amargor pela alta concentração de sais de cálcio, magnésio e sulfato (MORADO, 2009). Suas características físico-químicas podem viabilizar ou inviabilizar a produção de determinado estilo de cerveja.

Uma água que precisa de muitas correções de qualidade requer um tratamento mais minucioso, o que irá resultar em um aumento no custo do produto final. Atualmente, as cervejarias tratam a água por osmose reversa para depois acrescentar sais minerais de acordo com o estilo de cerveja a ser fabricado (SANTOS, DINBAM e ADAMES, 2013; EUWA, 2006). É necessário que a fábrica esteja instalada próxima a uma fonte de água de boa qualidade, pois a indústria cervejeira consome grandes volumes de água e também é importante que a fonte utilizada possua água em abundância. Em média, uma indústria cervejeira consome 10 litros de água, para cada litro de cerveja produzido. Os principais parâmetros analisados na água estão dispostos na Tabela 01. 
Tabela 01: Especificações físico-químicas da água para a produção de cerveja

\begin{tabular}{|c|c|c|}
\hline Parâmetro & Umidade & Especificação \\
\hline Aparência & - & Límpida e clara \\
\hline Sabor & - & Insipida \\
\hline Odor & - & Inodoro \\
\hline $\mathrm{pH}$ & $\mathrm{pH}$ & $6,5-8,0$ \\
\hline Cor & $\mathrm{mg} \mathrm{Pt} / \mathrm{L}$ & $0-5$ \\
\hline Turbidez & NTU & Menor que 0,4 \\
\hline Matéria orgânica & $\mathrm{mg} \mathrm{O}_{2}$ cons./L & $0-0,8$ \\
\hline Sólidos dissolvidos totais & $\mathrm{mg} / \mathrm{L}$ & $50-150$ \\
\hline Dureza total & $\mathrm{mg} \mathrm{CaCO}_{3} / \mathrm{L}$ & $18,0-79,0$ \\
\hline Alcalinidade & $\mathrm{mg} \mathrm{CaCO}_{3} / \mathrm{L}$ & $0,8-25,0$ \\
\hline Sulfatos & $\mathrm{mg} \mathrm{SO}_{4} / \mathrm{L}$ & $1-30$ \\
\hline Cloretos & $\mathrm{mg} \mathrm{Cl} / \mathrm{L}$ & $1-20$ \\
\hline Nitratos & $\mathrm{mg} \mathrm{NO}_{3} / \mathrm{L}$ & Ausência \\
\hline Nitritos & $\mathrm{mg} \mathrm{NO}_{2} / \mathrm{L}$ & Ausência \\
\hline Sílica & $\mathrm{mg} \mathrm{SiO}_{2} / \mathrm{L}$ & $1-15$ \\
\hline Cálcio & $\mathrm{mg} \mathrm{Ca}{ }^{2+} / \mathrm{L}$ & $5-22,0$ \\
\hline Magnésio & $\mathrm{mg} \mathrm{Mg}^{2+} / \mathrm{L}$ & $1-6$ \\
\hline Ferro & $\mathrm{mg} \mathrm{Fe} / \mathrm{L}$ & Ausência \\
\hline Alumínio & $\mathrm{mg} \mathrm{Al} / \mathrm{L}$ & Máx. 0,05 \\
\hline Amoníaco & $\mathrm{mg} \mathrm{N} / \mathrm{L}$ & Ausência \\
\hline $\mathrm{CO}_{2}$ livre & $\mathrm{mg} \mathrm{CO}_{2} / \mathrm{L}$ & $0,5-5$ \\
\hline
\end{tabular}

Fonte: REINOLD (2008).

\section{Malte de cevada}

A produção brasileira de cevada para fins cervejeiros está concentrada em três estados da Região Sul do Brasil (MINELLA, 2013). De acordo com Andrade, Mega e Neves (2011), a cevada é uma planta da família das gramíneas e é nativa de climas temperados. Após a colheita, os grãos de cevada são enviados para as maltarias, onde são submetidos à germinação controlada. O malte é a própria cevada germinada. Maltear significa quebrar a dormência do grão (REBELLO, 2009), sendo considerado um processo no qual se obtém a degradação do endosperma dos grãos de cevada, além da acumulação de enzimas ativas nestes grãos (BRIGIDO; NETTO, 2006).

Os principais tipos de cevada utilizados na fabricação de cerveja se diferem pelo número de fileiras de grãos: a de duas e a de seis fileiras. A cevada de duas fileiras contém duas fileiras de grãos na mesma espiga, esta é a mais utilizada, pois é composta de grãos maiores e mais uniformes. Essa mesma se subdivide em dois subgrupos principais: a cevada de haste ereta (Hordeum distichum erectum) e a cevada de haste curta (Hordeum distichum nutans) (CARVALHO, 2007). Somente 15\% dos grãos de cevada se destinam a produção da cerveja, o 
Mundialmente, a cevada é considerada como o quinto grão mais empregado na produção da cerveja, superando outros tipos que também podem ser utilizados, tais como: arroz, milho, trigo e soja. Abaixo são descritas algumas características que explicam a preferência desse cereal que a torna mais adequada para a produção de cerveja do que outros cereais.

Segundo Oliveira (2011): possui alto teor de amido, o que a torna atrativa em termos de custo por ser mais barata e mais fácil de maltear que outros cereais; quando maltada, possui um teor elevado de enzimas que ajudam no processo de fabricação do mosto, principalmente na quebra do amido em açúcares; contém outras proteínas que proporcionam equilíbrio nos efeitos em relação à espuma, ao corpo e a sua estabilidade coloidal; possui teor de lipídios relativamente baixo, o que é vantajoso para a estabilidade de sabor da bebida; processo de malteação inicia a partir da etapa de umidificação dos grãos de cevada, denominada maceração, seguido da etapa de germinação, onde o sistema enzimático do grão que irá agir sobre a reserva de amido do mesmo irá fornecer carbono e energia para o desenvolvimento do embrião. Após isso, o processo atinge um ponto de germinação, então o processo é cessado através de secagem (BOULTON, 2006; PORTO, 2011).

\section{Lúpulo}

O Humulus lupulus, conhecido vulgarmente como Lúpulo, planta trepadeira pertencente à família da morácea e originária de zonas temperadas. É uma planta dióica, que quer dizer que produz flores masculinas e femininas. Na produção de cerveja utilizam-se apenas das flores femininas, que contêm a substância lupulina quando fecundadas, que confere o amargor, aroma e algumas propriedades medicinais (JÚNIOR, VIEIRA e FERREIRA, 2009).

Os compostos ativos de aroma de lúpulo estão presentes nas glândulas das flores fêmeas da planta (Figura 01) e estas, geralmente, apresentam de 4 a $5 \mathrm{~cm}$ de comprimento. O lúpulo constitui-sede óleos essenciais (0,2-3\%), $\beta$-ácidos também chamados lupulonas (1,5-9,5\%) e de $\propto$-ácidos (2,0-16,0\%) (NOONAN, 1996; SILVA; FARIA, 2008), também chamados humulonas. As proporções de cada composto dependem da variedade da planta. 


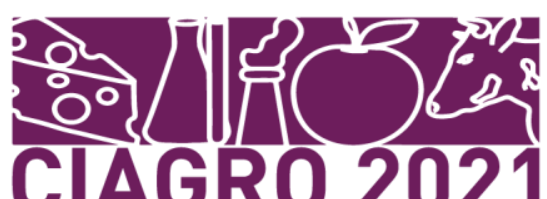

Figura 01: Corte longitudinal das Flores Fêmeas de Lúpulo

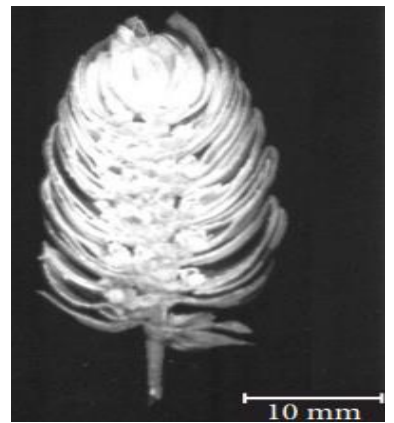

Fonte: SILVA E FARIA (2008).

Os lúpulos podem ser classificados em lúpulo aroma e de amargor. Os óleos essenciais do lúpulo possuem composição bastante complexa, apresentando mais de 200 compostos (SHARP; LAWS, 1981).

Os $\beta$-ácidos contribuem para uma menor intensidade para o amargor. A ação bactericida age no transporte de metabólitos na membrana celular e altera o $\mathrm{pH}$ intracelular, enquanto que os $\alpha$-ácidos são isomerizados através de calor produzindo os iso- $\alpha$-ácidos, que são constituídos principalmente por isohumulona, isocohumulona e isoadhumulona. Com isso, são considerados mais amargos que os ácidos originais não isomerizados, sendo responsáveis por mais de 70\% do amargor detectado sensorialmente em cerveja (SILVA; FARIA,2008). A Tabela 02 apresenta a porcentagem de cada um dos compostos amargos no lúpulo.

Tabela 02: Especificações físico-químicas da água para a produção de cerveja

\begin{tabular}{cccc}
\hline$\propto$-ácidos & Quantidade & $\beta$-ácidos & Quantidade \\
humulona & $35-70 \%$ & humulona & $30-55 \%$ \\
cohumulona & $20-55 \%$ & cohumulona & $20-55 \%$ \\
adhumulona & $10-15 \%$ & adhumulona & $5-10 \%$ \\
prehumulona & $1-10 \%$ & prehumulona & $1-3 \%$ \\
posthumulona & $1-5 \%$ & posthumulona & Valor não identificado \\
\hline
\end{tabular}

Fonte: VARNAM;SUTHERLAND (1997).

O lúpulo é utilizado em pequena quantidade, sendo necessários de 40 a 300 gramas de lúpulo para produzir 100 litros do produto final. Ao contrário do malte, o lúpulo não altera o teor alcoólico nem o corpo da cerveja (MORADO, 2009). Os principais países produtores são Alemanha, Estados Unidos, República Checa, Inglaterra e Nova Zelândia, que produzem mais de $80 \%$ do lúpulo mundial (CARVALHO, 2007).

A Tabela 03 indica a composição química do lúpulo com relação aos principais componentes e as respectivas quantidades. 
Tabela 03: Composição química do lúpulo

\begin{tabular}{cc}
\hline Componente & Quantidade \\
Água & $8-14 \%$ \\
Proteínas & $12-24 \%$ \\
Resinas Totais & $12-21 \%$ \\
Ácidos - alfa & $4-10 \%$ \\
Ácidos - beta & $3-6 \%$ \\
Taninos & $2-6 \%$ \\
Celulose & $10-17 \%$ \\
Cinzas & $7-10 \%$ \\
Óleos essenciais & $0,5-2,0 \%$ \\
\hline
\end{tabular}

Fonte: MORADO (2009).

\section{Levedura}

O fermento é o ingrediente utilizado para realizar o processo fermentativo dos açúcares no mosto cervejeiro. O fermento cervejeiro comumente utilizado para a produção de cervejas é a levedura Saccharomyces, com cepas de alta e baixa fermentação - Ale e Lager, respectivamente (CARVALHO, 2007).

As leveduras são microrganismos eucarióticos, predominantemente unicelulares, pertencentes ao Reino Fungi. Possui habilidade de metabolizar eficientemente os constituintes do mosto, que é um caldo resultante da mistura fervida de malte e água, rico em açúcares fermentáveis. Esse caldo é filtrado, para receber o lúpulo e o fermento ser transformado em álcool e gás carbônico a fim de produzir uma cerveja com qualidade e estabilidade sensorial satisfatória (CARVALHO et al., 2007).

As leveduras mais utilizadas em cervejaria são de duas espécies do gênero Saccharomyces: Saccharomyces cerevisiae (alta fermentação) e Saccharomyces uvarum (baixa fermentação) (EMBRAPA, 2010 apud OLIVEIRA, 2011).

Morado (2009) destaca que por ser fundamental na formação de aromas na cerveja, é de grande importância que a cultura de leveduras seja a mais pura possível, isenta de leveduras "mutantes" e de microrganismos contaminantes (bactérias e leveduras selvagens), sendo indispensável à assepsia das cervejarias durante a produção.

Para Dragone, Almeida e Silva (2010) o tipo de levedura está intrinsecamente ligado às características de sabor e aroma de qualquer cerveja em que é utilizada. Como principal produto da fermentação das leveduras é o álcool e o $\mathrm{CO}_{2}$, no entanto, inúmeros compostos são produzidos em menor proporção, e estes, são de grande importância no sabor da cerveja. A cepa da levedura, a temperatura e o $\mathrm{pH}$ da fermentação, o tipo e a proporção do adjunto quando utilizado e até mesmo o modelo do fermentador e a concentração do mosto são fatores que 
influenciam o sabor da cerveja na etapa de fermentação (KUCK, 2008).

Houg classificou as leveduras de acordo o seu comportamento durante o processo fermentativo, sendo leveduras tipo Lager (ou de baixa fermentação) as que decantam no fundo do fermentador e levedura do tipo Ale (ou alta fermentação) as que tendem a flutuar sobre a superfície do mosto.

\section{Aditivos}

\section{Antioxidantes}

Tem como função evitar a ação do oxigênio, que é o principal fator da deterioração das gorduras dos alimentos. Ao sofrerem transformações, essas gorduras alteram o sabor e odor dos alimentos, tornando-os impróprios para o consumo. A incorporação do oxigênio na bebida faz com que acelere a deterioração do produto (MENDA, 2011).

\section{Acidulantes}

Os acidulantes têm um papel importante, pois colaboram no realce do sabor da bebida, regula a doçura do açúcar, acentuam o sabor ácido, regulam o pH e colaboram na inibição dos microrganismos (MENDA, 2011). Atuam como adjunto de aroma e sabor, largamente encontrados na natureza e disponíveis comercialmente na forma de soluções aquosas que são incolores, inodoras, viscosas e não voláteis (CARVALHO, 2007).

\section{Estabilizantes}

Os estabilizantes mantêm as características físicas das emulsões e suspensões com a finalidade de aumentar a viscosidade. São adicionados às cervejas destinadas ao engarrafamento como ao embarrilamento, ambas são à base de alginatos (MENDES, 2004). Exemplos de estabilizantes são a polivinilpirrolidona (PVP) e a carboximetilcelulose (CMC, um polímero derivado da celulose), ambas solúveis em água (ROSA e AFONSO, 2015).

\section{Antiespumantes}

Agentes antiespumantes, livres de Ferro, Cobalto ou Níquel, atuam regulando a formação de espumas, minimizando a incidência de formação de espuma e também atuando 
como desespumante de ação imediata no processo de fermentação alcoólica. Os fermentadores

de aço comum têm de ser adequadamente revestidos para evitar a contaminação com íons metálicos (FOOD INGREDIENTS BRASIL, 2014).

\section{Processo para a fabricação da cerveja}

O processo de produção de cerveja artesanal está delineado no fluxograma da Figura 03, embora as cervejas de mesma classificação sejam produzidas utilizando basicamente o mesmo processo, elas podem apresentar algumas variações de um tipo para outro (OLIVEIRA, 2011). As etapas do desenvolvimento da cerveja estão descritas a seguir:

\section{Malteação}

O malte, cevada maltada é a principal fonte de substâncias químicas com atividade sensorial (gustativa ou olfativa), encontradas na cerveja, seja por via direta, seja através das transformações que ocorrem durante a produção do mosto e a fermentação (GALVÃO, 1997). O processo de malteação é constituído de três etapas: maceração, germinação e secagem. $\mathrm{Na}$ maceração, a cevada é colocada em tanque cilíndrico para ser macerada com água. A água deve estar na temperatura entre 5 e $18^{\circ} \mathrm{C}$ e é trocada a cada 6 a 8 horas.O oxigênio necessário à respiração do embrião da cevada é fornecido através da injeção de ar nos tanques. O processo termina em dois dias, quando a cevada atinge 42 a $48 \%$ de umidade, nesse ponto há o aparecimento da radícula (AQUARONE, 2011 LORENA, 2015).

\section{Preparo do Mosto}

O tipo de mosturação depende do tipo e da composição da cerveja que se deseja obter, agregando conhecimentos da quantidade desejada de açúcares, substâncias protéicas, consistência da espuma, dentre outras (DRAGONE; ALMEIDA e SILVA, 2010). Nesta etapa ocorre a moagem do malte que tem como objetivo quebrar o grão e expor o amido contido em seu interior. É um processo puramente físico em que o malte é colocado no interior de um moinho, que ao cortar/danificar a casca das sementes promove a exposição do amido do endosperma (MATOS, 2011).

A moagem promove a diminuição do tamanho da partícula do amido, aumentando assim, a velocidade de hidrólise do amido (OLIVEIRA, 2011). É considerável que a moagem 
não seja muito severa para que a fase filtração não seja prejudicada, porém se a moagem for muito grosseira, não atingirá o seu objetivo, que é aumentar a superfície de contato do substrato amiláceo com as enzimas do malte, facilitando sua hidrólise (OETTERER; REGITANOD'ARCE; SPOTO, 2006).

Na mosturação ou brassagem ocorre a mistura do malte moído com água, submetendoo a diferentes temperaturas por períodos de tempo determinados para que o amido venha a se solubilizar e também ativar enzimas proteolíticas e de sacarificação, formando uma solução chamada de "mosto" (MORADO, 2009). O objetivo deste procedimento consiste em promover a gomificação e posterior hidrólise do amido a açúcares. $\mathrm{O}$ pH e a temperatura interagem para controlar a degradação do amido e das proteínas (VENTURINI, 2005).

A filtração da mostura é extremamente importante para a qualidade da cerveja, onde é realizada em um recipiente denominado tina de filtração, com a finalidade de separar o mosto líquido do bagaço de malte. Durante a filtração, o mosto flui por gravidade através de uma superfície filtrante constituída pelas próprias cascas do malte. Este processo é seguido por sucessivas lavagens do elemento filtrante com água a $76^{\circ} \mathrm{C}$, a fim de recuperar a maior parte do extrato líquido que fica retido no bagaço (OETTERER; REGITANO-D’ARCE; SPOTO, 2006), pois nessa temperatura a viscosidade do mosto diminui, diluindo os açúcares, que terão mais facilidade para se livrarem dos sólidos do bagaço, diminuindo dessa forma as perdas. As enzimas serão então inativas, sendo bloqueado o desenvolvimento bacteriano (REITENBACH, 2010).

Na primeira filtragem, o líquido passa através da camada de cascas do malte depositadas no fundo da tina, formando assim, uma camada filtrante, constituindo o mosto primário. Já na segunda filtragem a camada de cascas que se encontra na tina de mosturação é então lavada com água por uma ou mais vezes, para recuperar a maior parte do extrato líquido que fica retido no bagaço após a filtração (KUCK, 2008).

Piccini, Moresco e Munhos (2002) destacamque a turbidezdo mosto que sai do processo de filtragem deve ser a mínima possível, devido ao fato da cerveja ter um número bastante grande de sólidos que precipitam ao longo do processo, tendo uma quantidade definida de sólidos que devem ser retirados nos três processos de filtração.

Após a filtração, o mosto é encaminhado para uma tina de fervura, iniciando assim a sua fervura a aproximadamente $100^{\circ} \mathrm{C}$, o qual permitirá a inativação enzimática e a evaporação da água. O bagaço que ficou na tina, denominado torta, deve ter menos de $1 \%$ de extratos solúveis e pode ser utilizado na fabricação de rações para animais. (OETTERER; REGITANOD’ARCE; SPOTO, 2006). 
Além destas transformações, o lúpulo deve ser adicionado junto com os componentes

do mosto, em altas temperaturas. A fervura do mosto tem que ser intensa, pois é responsável pela esterilização do mosto e também exerce função importante favorecendo a obtenção de aroma, sabor, cor e esterilidade microbiológica da cerveja, devido à ação da caramelização e reação de Maillard (JAY, 2005). A adição de lúpulo ou lupulagem, normalmente ocorre em duas etapas, à primeira visando conferir amargores e a segunda prestando-se à adição de aromas florais, herbais e mesmo condimentados, acrescentados no mosto durante a cocção (MORADO, 2009).

\section{Fervura do mosto}

De acordo com Garcia-Cruz, Foggetti e da Silva (2008) e Matos (2011), os principais objetivos da fervura são: estabilização biológica, o mosto é um meio ótimo para o desenvolvimento de microrganismos que possa vir a contaminar a produção nas operações precedentes, por isso na fervura é visada a esterilização; estabilização bioquímica onde as enzimas que se mantiverem ativas são inativadas; estabilizações físico-químicas que as proteínas de maior cadeia são desnaturadas, floculando, precipitando e, com elas, acabam decantando, também, polifenóis, taninos e outras substâncias que serão retiradas posteriormente.

Extração e transformação dos componentes do lúpulo, que pela fervura o amargor e aromas do lúpulo são extraídos; concentração do mosto, que na filtração é usada água para extrair o extrato residual do bagaço; com a fervura faz-se a evaporação do excesso de água usada, deixando o mosto na densidade desejada; e outras transformações, como a formação de melanoidinas (combinação de açúcares simples com aminoácidos). Estas substâncias contribuem para o aroma e para a cor da cerveja.

Conforme Morado (2009), após a fervura do mosto sucede a separação do trub aglutinado protéico - por um processo chamado whirlpool, o qual utiliza a força centrípeta para fazer o trub se acumular no centro do tanque e logo pode ser feito o resfriamento, fundamental para que o mosto atinja a temperatura adequada para a fermentação. Se não ocorresse a separação do trub, a cerveja absorveria características desagradáveis a seu aspecto sensorial e assim adquirir um amargor não esperado, com coloração escura, além da desestabilização da espuma (BAMFORTH, 2005). 


\section{Fermentação}

No resfriamento e na aeração do mosto o principal intuito é a inoculação das leveduras, que irão fermentar o extrato para a elaboração da cerveja. A temperatura depende do tipo de cerveja que se deseja obter, que deve estar diretamente ligada ao tipo de fermentação. A aeração é um processo fundamental para a fabricação de cerveja, pois trazem consequências diretas nos processos finais da cerveja. Em função disso, deve-se fazer uma aeração adequada de modo a facilitar a ação das leveduras e a retirada de compostos do mosto que provocariam turbidez na cerveja (VENTURINI, 2005).

Os carboidratos fermentescíveis presentes como a maltose, maltotriose, glicose, entre outros, são metabolizados pelas leveduras. Subprodutos podem desenvolver-se durante o processo de fermentação e componentes do mosto são assimilados pela levedura, sendo denominados produtos secundários da fermentação (DRAGONE; ALMEIDA; SILVA, 2010).

A levedura empregada deve ser inoculada a uma solução de $100 \mathrm{~mL}$ do mosto, depois de certo tempo fermentando, este passa para um recipiente de $1000 \mathrm{~mL}$ de mosto (inoculo). Depois de ter passado o tempo de crescimento da levedura, o mesmo é inoculado ao mosto principal nos tanques de fermentação. Tal processo serve tanto para as leveduras de fermentação alta, quanto para as de fermentação baixa (JACKSON, 2007).

Depois de realizado este processo o produto deve ser maturado, finalizando o processo fermentativo, além de melhorar as características da qualidade da cerveja como sua carbonatação e formação de ésteres responsáveis pelo aroma e sabor (FERREIRA e BENKA, 2014). A fermentação confere à bebida seu teor alcoólico, além de uma parte da carbonatação e espumação. Normalmente, é feita à proporção de $1 \%(\mathrm{v} / \mathrm{v})$ de fermento em relação ao mosto e o tempo de fermentação pode variar de acordo com a cervejaria e o tipo de cerveja que se pretende (OETTERER, REGITANO-D'ARCE e SPOTO, 2006).

O cuidado para que se tenha uma boa cerveja é indispensável, tais como: a seleção de uma boa cepa de levedura (a levedura boa deve flocular e decantar no fundo do tanque fermentador ao final do processo); se a cerveja será de baixa ou de alta fermentação; concentração celular a ser utilizada; dados de crescimento e morte celular do microrganismo; tempo e como determinar o término da fermentação (GARCIA-CRUZ, FOGGETTI E DA SILVA, 2008 apud MATOS, 2011).

As cervejas do tipo Lager são produzidas por leveduras de alta fermentação, a temperatura inicial do mosto deve ficar entre a faixa de 14 a $20^{\circ} \mathrm{C}$. Após 36 horas de fermentação, a temperatura do mosto é elevada para 20 a $25^{\circ} \mathrm{C}$ e depois de 72 horas diminui-se para $17^{\circ} \mathrm{C}$. Nas 
últimas 10 horas de fermentação as leveduras tendem a subir para a superfície do mosto. Para

as cervejas do tipo Ale produzidas a partir de leveduras de baixa fermentação, a temperatura do mosto deve estar entre 6 a $12^{\circ} \mathrm{C}$ e depois elevada para 10 a $15^{\circ} \mathrm{C}$ nos primeiros 3 a 5 dias da fermentação. No final, a temperatura é diminuída e a levedura passa a decantar (OETTERER; REGITANO-D'ARCE; SPOTO, 2006).

\section{Maturação}

O produto resultante da fermentação principal é a cerveja "verde", onde ainda existem leveduras em suspensão e certa quantidade de material fermentescível e passará por uma fermentação secundária, conhecida como maturação.Os objetivos principais da maturação são: arredondamento do paladar e aroma, clarificação da cerveja, amadurecimento e eliminação de substâncias sulfonadas que são arrastadas pelo gás carbônico (ALVISI, 2011).

Segundo Morado (2009), dado início a maturação grande parte dos açucares terá sido metabolizado e transformado em álcool etílico, dióxido de carbono, glicerol ácido cético, álcoois superiores e ésteres. Cerca de $10 \%$ do total de ésteres da cerveja são formados durante a maturação. Ocorrem além da redução dos teores de compostos sulfídricos, como o diacetil, acetaldeído e ácido sulfídrico, também uma atenuação no amargor do lúpulo onde é estabelecido o sabor final da cerveja (VENTURINI, 2005). A cerveja tipo Ale passa por um período de maturação de poucos dias, geralmente menos de um mês. A Ale forte pode precisar de um período de maturação de até um ano (EVANGELISTA, 2012).

\section{Tratamento e Armazenamento}

A cerveja pode ser armazenada em garrafas ou latas de alumínio e deve passar pelo processo de pasteurização. A pasteurização é feita com objetivo de proporcionar estabilidade biológica à cerveja, através da destruição de microrganismos pelo calor (CARVALHO et al., 2006). Por fim, a pasteurização que consiste em diminuir a carga microbiana que, se presentes, podem prejudicar as características da cerveja. Assim, a pasteurização costuma ser realizada a temperaturas por volta de $70^{\circ} \mathrm{C}$ (KUCK, 2008), porém críticos alegam que esta operação prejudica o paladar, conferindo adstringência adicional e até mesmo sabores de "queimado" à bebida (MORADO, 2009). 
Torna-se possível comprovar que produzir cerveja, hoje, com toda a informação e tecnologia disponíveis, é fácil. No entanto, produzir cerveja de alta qualidade com formulação e protocolos originais, inovando e compreendendo o que se está fazendo, é algo um tanto quanto mais complexo, devido à quantidade de variações possíveis nos processos, exigindo do fabricante conhecimento científico para que se alcance o resultado desejado. As cervejas artesanais geralmente têm uma qualidade sensorial diferenciadas quando comparadas as cervejas tradicionais. As cervejas populares têm o intuito de agradar à grande maioria dos consumidores da maneira mais barata possível, e conseguem manter um nível e padrão de qualidade invejável por qualquer empresa, devido ao controle que têm dos processos de produção, distribuição, etc. Ademais, conclui-se também que as cervejas artesanais, por sua vez, têm o intuito de agradar um público restrito, no qual estão a procura de cervejas com características sensoriais diferenciadas das demais.

\section{REFERÊNCIAS}

ALVISI, F. Manual de Treinamento Técnico Cervejeiro. AmBev, 2011.

ASSIS, G.P.; LIMA, B.M.B.; DOS SANTOS, L.M.R. Physical and chemical analysis of ipa beer of the southern fluminese region. Análises físico-químicas de cerveja tipo IPA da Região Sul Fluminense. Revista Teccen. 2020 Jul./Dez.; 13 (2): 47-51.

ANDRADE C. J.; MEGA F. J.; NEVES E. A Produção da Cerveja no Brasil. Ciência, Tecnologia, Inovação e Oportunidade, vol 1, nº 1. Barra do Bugres 2011.

ARNOLD, JOHN P. Origin and History of Beer and Brewing: From Prehistoric Times to the Beginning of Brewing Science and Technology. Reprint Edition by BeerBooks, Cleveland, OH, 2005.

BAMFORTH, C. W. Food, fermentation and micro-organisms. Blackewell Science Ltda Blackwell Publishing company. 2005. .

BRASIL. MINISTÉRIO DA AGRICULTURA. SECRETARIA NACIONAL DE DEFESA AGROPECUÁRIA. Decreto $\mathbf{n}^{\mathbf{0}} \mathbf{6 . 8 7 1}$, de 04 de junho de 2009. Regulamentação da Lei $\mathrm{N}^{\circ}$ 8.918, de 14 de julho de 1994, sobre a padronização, a classificação, o registro, a inspeção e a fiscalização da produção e do comércio de bebidas. Diário Oficial da União, Brasília, 04 de junho de 2009.

BRIGIDO R. V.; NETTO M. S. Produção de Cerveja. Trabalho apresentado à disciplina de Engenharia Bioquímica da Universidade Federal de Santa Catarina. Florianópolis, 2006. 
manual para la industria cervecera. 2.ed. Peru: Associacón de Maestros Cerveceros de las Américas, 1977. 550p.

CARVALHO, GBM; DRAGONE, G; BENTO, CV; SANTOS, DT; SARROUH, BF; FELIPE, MGA; ALMEIDA E SILVA, JB. Utilização da banana como adjunto na obtenção de mosto cervejeiro de alta densidade: um estudo para fim biotecnológico clássico inédito. In: Congresso Mineiro de Propriedade Intelectual, Agosto 9-11, UFJF, Juiz de Fora - MG, 2006.

CARVALHO, G.B.M., ROSSI, A.A., ALMEIDA e SILVA, J.B. Elementos biotecnológicos fundamentais no processo cervejeiro: $2^{\mathrm{a}}$. parte, A fermentação. Revista Analytica, v.26, p.46 54, 2007.

CARVAlHO, L. G. Dossiê Técnico. Produção de cerveja. Rede de Tecnologia do Rio de Janeiro, Rio de Janeiro, mar. 2007.

CERVBRASIL. Anuário 2015. Disponível em: http://www.cervbrasil.org.br/arquivos/ANUARIO_CB_2015_WEB.pdf. Acesso em: 07 março 2018.

DINSLAKEN, D. Manual do Cervejeiro Caseiro. $1^{\text {o }}$ edição. V.1. Edição virtual, 2016.

DRAGONE, G. ALMEIDA e SILVA, J.B. Bebidas Alcoólicas: Ciências e tecnologia. V.1. São Paulo: Edgard Blücher, 2010.

EUWA, M. EUMANN. Water in brewing. In: Brewing New technology. Published in North America, 2006.

EVANGELISTA, R. R. Análise do processo de fabricação industrial de cerveja. São Paulo: Fatec Araçatuba, 2012, 50 p.

FERREIRA, A. de S.; BENKA, C.L. Produção de Cerveja Artesanal a Partir de Malte Germinado Pelo Método Convencional e Tempo Reduzido de Germinação. Trabalho de Conclusão de Curso (Tecnólogo em Alimentos, no Curso Superior de Tecnologia em Alimentos) - Universidade Tecnológica Federal do Paraná. 2014.

FERREIRA, J. Fermentação. Salvador, BA, 2007.

FERREIRA, A. C., PEREIRA, M. M. O., REZENDE, D. C. E VIEIRA, A. S. Simbolismo e Construção da Identidade por meio do Consumo de Cerveja Artesanal. Revista de Negócios, 23(3), 19-35, 2018.

FERREIRA, A. C., PEREIRA, M. M. O., REZENDE, D. C. E VIEIRA, A. S. Motivações de compra e hábitos de consumo: um estudo com apreciadores de cerveja artesanal. Revista da Micro e Pequena Empresa, 13(1), 12-31, 2019.

JACKSON, M. Cerveja. 2 ed. Rio de Janeiro: Editora Zahar. 2007.

JAY, J. M. Microbiologia de alimentos. 6 ed. Porto Alegre: Artmed. 2005. 
JÚNIOR, A. A. D.; VIEIRA, A. G.; FERREIRA, T. P. Processos de produção de cerveja.

Revista Processos químicos. p. 61-71, jul./dez. 2009.

KENNING, DAVID. Beers Of the Word. London: Parragon Books Ltd., 2010.

KUCK, L. S. Cerveja: Sabor e Aroma. 2008. 47 f. Trabalho acadêmico do Curso de Bacharelado em Química de Alimentos - Universidade Federal de Pelotas, RS.

KUNZE, W. Technology brewing and malting. Berlim: VLB, 1997. p. 433-435.

MADRID, A. Manual de indústrias de alimentos. 1.ed. São Paulo: Varela, 1996. p. 599.

MARCUSSO, E. F. AS MICROCERVEJARIAS NO BRASIL ATUAL: Sustentabilidade e Territorialidade. 171 f. Dissertação. Mestrado em Sustentabilidade na Gestão Ambiental.Universidade Federal de São Carlos (UFSC). Sorocaba - SP. 2015

MARCONI, M. A; LAKATOS, E. M. Técnicas de Pesquisa: planejamento e execução de pesquisas, amostragens e técnicas de pesquisa, elaboração, análise e interpretação de dados. 7 ed. São Paulo: Atlas, 2010.

MATSUBARA, AMANDA KAORI; PLATH, ARIANE R. Desenvolvimento de Cerveja Artesanal de Trigo adicionada de Gengibre (ZingiberofficinaleRoscoe). 51f. Trabalho de Conclusão de Curso (Curso Superior de Tecnologia em Alimentos). Universidade Tecnológica Federal do Paraná. Londrina, 2014.

MATOS, RICARDO AUGUSTO GRASEL. Cerveja: Panorama do Mercado, Produção Artesanal, e Avaliação de Aceitação e Preferência. 2011. Trabalho de Conclusão de Curso. Florianópolis - SC.

MENDA, M. Refrigerantes. Rio de Janeiro: Conselho Regional de Química 4ª Região, 2011.

MELLO, J. A V. B.; SILVA, JK. L. M. Requisitos de produto para um projeto de cerveja artesanal. Innovar, vol. 30, núm. 77, 2020.

MENDES, DIAS, A. Processamento de cerveja. Universidade Federal de Santa Catarina, Florianópolis, SC), 2004.

MINELLA E. Reunião Nacional de Pesquisa de cevada (29: 2013: Passo Fundo, RS). Indicações técnicas para a produção de cevada cervejeira nas safras 2013 e 2014. Editado por Euclydes Minella. Passo Fundo: Embrapa Trigo,105 p, 2013.

MORADO, R. Larousse da Cerveja, $1^{\text {a }}$ edição. São Paulo, SP: Larousse do Brasil, 2009. 357p.

MORADO, RONALDO. A rivalidade deixada de lado para dar lugar ao prazer de degustar bebidas de qualidade. SP, 2015.

OLIVEIRA, N. A. M. Leveduras utilizadas no processo de fabricação da cerveja. 2011. 45f. Monografia (Pós-graduação em Microbiologia) - Instituto de Ciências Biológicas, UFMG, Belo Horizonte, 2011. 44p. 
e Tecnologia de Alimentos. Barueri, SP: Manole, 612p, 2006.

PATTINSON, RON. European Beer Statistics: Volume of World Beer Production, 2006.

PICCINI A. R., MORESCO, C. e MUNHOS, L. Cerveja. 2002. Acessado em: http://www.ufrgs.br/alimentus1/feira/prcerea/cerveja/defini.htm.

PORTO, PAULA DE D. Tecnologia de fabricação de malte: uma revisão. 2011. 58 f. Trabalho de Conclusão de Curso (Graduação) - Universidade Federal do Rio Grande do Sul, Porto Alegre, 2011.

REBELlO, F. D. F. P. Produção de cerveja. Revista Agro geo ambiental. Inconfidentes. Dezembro 2009.

REINOLD, M. R. Fatores importantes para a elaboração de uma cerveja de qualidade. Revista Indústria de Bebidas: Fc Santos, 2008, Ano 07, № 41.

REITENBACH, A. F. Desenvolvimento de cerveja funcional com adição de probiótico: Saccharomyces boulardii. Não paginado. Dissertação (Mestrado) - Universidade Federal de Santa Catarina, Centro Tecnológico, Programa de Pós-Graduação em Engenharia de Alimentos, Florianópolis, 2010.

ROSA, N. A.; AFONSO, J. C. A. Química da Cerveja. Química Nova, v. 37, N² 2, p. 98-105, 2015.

SEBRAE - Serviço Brasileiro de Apoio às Micro e Pequenas Empresas - Potencial de Consumo de Cervejas no Brasil, 2014.

SILVA, PAULO HENRIQUE ALVES DA; FARIA, FERNANDA CAROLINA DE. Avaliação da intensidade de amargor e do seu princípio ativo em cervejas de diferentes características e marcas comerciais. Ciência e Tecnologia de Alimentos. p. 902-906, out.-dez. 2008

SHARP, F. R.; LAWS, D. R. J. The essential oil of hops - a review. Journal of the Institut of Brewing, v. 87, p. 96-107, 1981.

SIQUEIRA, P. B. Estudo da cinética bioquímica e sensorial de diferentes tipos de cervejas brasileira. 2007. 125f. Dissertação (Mestrado em Ciência de Alimentos) - Faculdade de Engenharia de Alimentos, Universidade Estadual de Campinas, Campinas, 2007.

VARNAM, A. H.; SUTHERLAND, J. P. Bebidas alcohólicas: I. Cerveza. In: Bebidas: Tecnologia, Química y Microbiologia. Zaragoza: Acribia, S.A., 1997. 487p.

VENTURINI, W. G. Cerveja. In: Tecnologia de Bebidas. 1.ed. São Paulo: Edgard Blücher, 2005. p. 550. 